\title{
A Study to Assess Awareness and Perceptions of Employees towards Performance Appraisal System in a Corporate Super-Specialty Hospital in Amritsar
}

\author{
Prabhjot Kaur Dilawari
}

Assistant Professor, Department of Sports Medicine and Physiotherapy, Guru Nanak Dev University, Amritsar, India

\begin{abstract}
Human resources of a healthcare organization is the most valuable asset which converts the available resources into efficient clinical services with or without the use of equipments. As services in a healthcare organization wholly depends on clinical efficiencies of the healthcare workers, hence adequate motivational tools to boost up the morale of workers and tap their potential fully are required. Performance appraisal is one of such tools which assesses the employees on the basis of the skills they possess, quality of services they deliver and knowledge and efficiency, and thereby, deciding the level of compensation, rewards and punishments, transfers and training needs in employees. Employee satisfaction towards performance appraisal depends on the transparent and bias free conduction of program, satisfaction with which can lead to the better health outcomes and increased organization outputs. The present survey study aims to find out the perception and awareness of 260 employees towards such system in a corporate hospital. The results revealed an above normal level of awareness and high level of satisfaction of employees towards the same.
\end{abstract}

Keywords: Performance Appraisal, Employee Satisfaction, Awareness, Effectiveness, Corporate Hospital.

\section{Introduction}

Human resources are valuable resources for any enterprise. They are vital as they possess required intelligence to make material, physical and financial resources productive and effective. Appraising human potential, in a scientific and systematic manner paves way for enhanced corporate performance ${ }^{1}$.

According to Heyel, "Performance Appraisal is the process of evaluating the performance and qualifications of the employees in terms of requirements of job for which he is employed for the purpose of administration including placement, selection for promotions, providing financial rewards and other actions which require differential treatment among the members of the group as distinguished from actions affecting all members equally."

This is usually evaluated in terms of quality, cost and time ${ }^{3}$.

After an employee has been selected, trained and motivated, he is apprised of his performance while on-job in terms of qualities and status.

In order to find out whether an employee is worthy of continued employment or not, and if so, whether he should receive a bonus, a pay rise or a promotion, his performance needs to be re-evaluated from time to time ${ }^{4}$.

The object of Performance Appraisal is to improve the efficiency of an enterprise by attempting to mobilize the best possible efforts from individuals employed in it.

Performance appraisal aims to determine how productive an employee is and whether the productivity of employee can be improved ${ }^{5}$.

Salary revision following a performance appraisal is a great motivating factor and a fair performance appraisal goes a long way towards reducing attrition rates.
The performance appraisal system is an important way to improve communication link between employees and employers gathering all the required information amending the grievances.

Methods of Performance Appraisal- critical incident method, weighted checklist method, paired comparison analysis, graphic rating scales, essay evaluation, behaviorally anchored rating scales, performance ranking method, $\mathrm{MBO}$, $360 \mathrm{deg}$, forced ranking, behavioral observation scales.

Self appraisal method is defined as an employees' own judgment about the quality of their work or the process of judging your own work ${ }^{6}$. They are helpful to employees to set personal goals and to identify areas of behavior that need improvement themselves which is an informal method that provides an excellent forum for input and feedback by superiors, also allowing supervisors to find out what employees expect from themselves and from organization or departments.

Outcomes of performance appraisal: Reduced employee stress, review of overall progress, linkage between current performance and employees goal, and development of specific action plans for future ${ }^{7}$, improved performance, reduced employee turnover, increased motivation, rewarding on the basis of performance and sense of equity among employees.

Detriments to effectiveness of Performance appraisal: Exemptions to the highly visible employees, conduct of performance appraisal to punish low performers, rewards on non performance, doubts in the minds of performers in the appraisals' after effects, organization politics that leads to disturbed performance of targeted employees, focus on extremes, appraisals focus on achievement of short term goals, support to autocrat supervisors, subjectivity of appraisals results and creation of emotional anguish in employees, use of vague qualities and irrelevant 


\section{International Journal of Science and Research (IJSR) \\ ISSN (Online): 2319-7064}

Index Copernicus Value (2013): 6.14 | Impact Factor (2015): 6.391

measurement criteria, use of useless checklists for evaluation, reluctance of appraisers to offer feedback, supervisors' misguidance to appraiser, inaccuracies at supervisors'/organization end ${ }^{8}$.

Role of performance appraisal in hospitals: An effective performance appraisal program assists the hospital in achieving its goals and objectives. Not only training needs are identified and addressed during a performance appraisal review but also hidden talent can be discovered as well. Through identifying these training needs, staff can perform their jobs at highest level and be in a better position to address patients, attendants, clients, members and customers concerns and questions. A well developed staff is more likely to be proactive, productive and resourceful, all of which helps give the hospital a competitive edge ${ }^{12}$.

Factors affecting effective performance appraisal satisfaction:

If the employees of an organization are satisfied with respect to performance appraisal system it indicates the degree to which subordinates are satisfied, provides a report of accuracy and fair evaluation of the performance, and improvement in their working relations with their supervisors.

Fairness: perception of fairness are important to all human resource process, for e.g. selection, compensation, particularly so, to the performance appraisal process 9 .

A good perception of the performance appraisal system will create a positive work atmosphere while a negative perception will create problems that will affect performance $^{10}$.

Acceptance by the users: employees must have trust on the accuracy and fairness of the performance appraisal system otherwise they are tremendous waste of time and money spent on implementation and development. It generates an atmosphere of cooperation and trust which reduces defensive behavior and rater-ratee conflict.

Performance feedback: it is an effective tool in changing employee work behavior and enhances employee's job satisfaction and performance ${ }^{11}$.

\section{Aims and Objectives of the Study}

- To diagnose whether the performance appraisal system is successful in identifying strengths and weaknesses of individual so as to identify the training needs in future.

- To assess whether employees are satisfied with the performance appraisal system in their organization and suitable recommendations to amend them.

\section{Methods and Procedures}

The present paper was a survey study conducted on randomly selected 260 employees working in different departments of Fortis Escorts Super-Specialty Hospital Amritsar through a well structured questionnaire data base in order to ascertain whether the appraisal system in the hospital is efficient enough to generate confidence and boost morale of the employees working there, thereby improving their efficiency leading to quality clinical service delivery to patients.

\subsection{Methodology}

Interaction was done with employees explaining them the purpose of study and obtaining consent. Sample was reassured of anonymity and voluntary participation to obtain honest views. The data was collected through a well structured close ended questionnaire database which was tabulated and analyzed with the help of simple statistical tools like computation of percentage using Nominal Scale to reach the assessment results.

\subsection{Inclusion Criteria}

- Employees available and willing for participation.

- Staff in job in the hospital for a minimum of 6 months or have undergone performance appraisal program at least once.

\subsection{Exclusion Criteria}

- Staff unwilling/ unavailable/ busy at the time of study.

- Under-trainees/ interns/ Freshly recruited staff who had not undergone the performance appraisal program even once.

\section{Results and Discussions}

An effective performance appraisal system can motivate the employees and tap their maximum potential thereby increasing the quality of service delivery. This study has aimed to assess the perception on the effectiveness of system of performance appraisal in the present work area.

\subsection{Demographic characteristics}

Total of 260 employees were chosen randomly from Fortis Escorts Super-specialty hospital Amritsar out of which 70 were males and 190 were females $(63.85 \%)$ under $18-30$ years age (Figure 1).

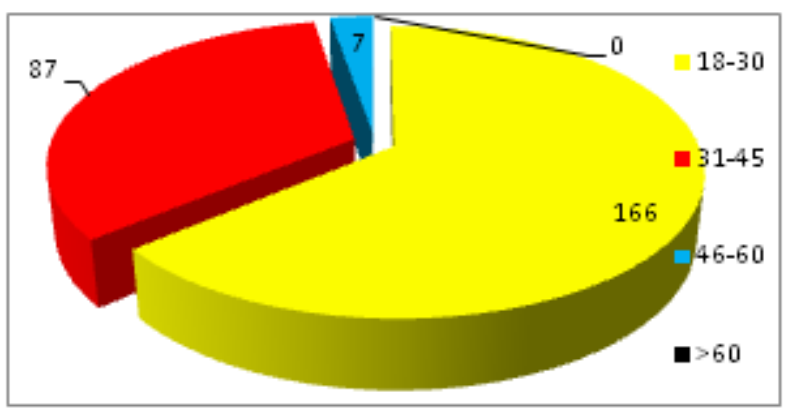

Figure 1: Sample distribution of age 


\section{International Journal of Science and Research (IJSR) \\ ISSN (Online): 2319-7064}

Index Copernicus Value (2013): 6.14 | Impact Factor (2015): 6.391

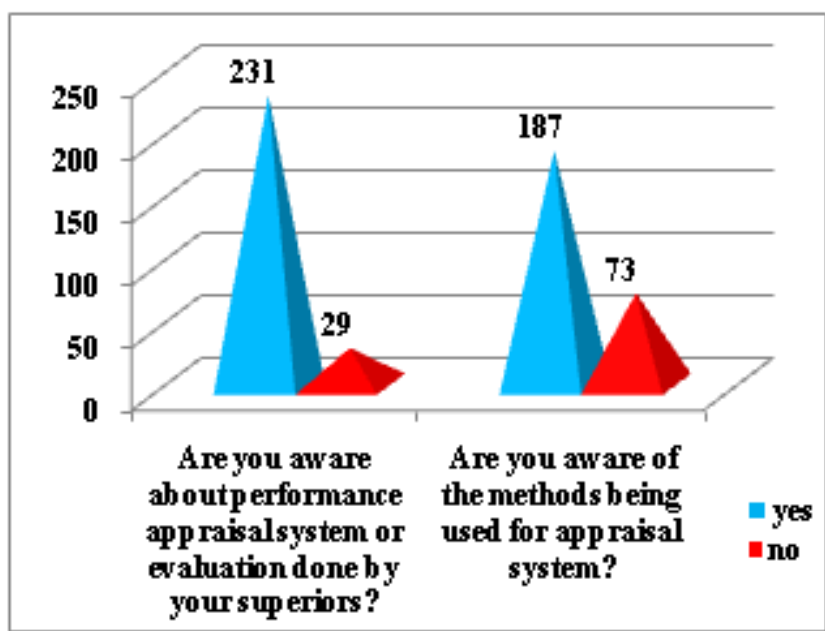

Figure 2: Awareness of Performance Appraisal system in Hospital

The majority (88.85\%) employees were found to be well aware of the existence of Performance Appraisal system functioning in the hospital although still a significant percentage $(71.92 \%)$ of sample were not very clear with the method being employed for conducting the same (mostly nurses).

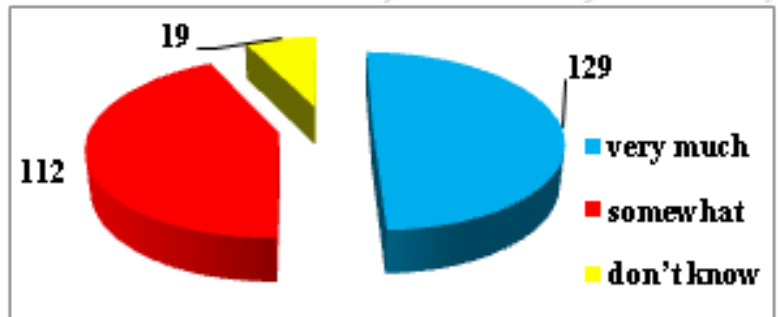

Figure 3: Are you aware of objectives of performance appraisal system

There was a mediocre level of awareness regarding the objectives of Performance appraisal system employed with $49.62 \%$ employees well aware, $43.08 \%$ employees in doubt and $7.31 \%$ altogether unaware of the objectives of conducting performance appraisal.

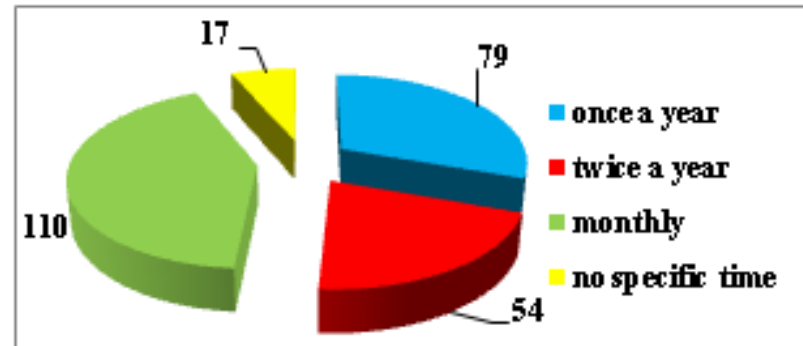

Figure 4: How many times performance appraisal system is conducted in organization in year?

Yearly Performance Appraisal is conducted in the hospital and the awareness of this frequency was known to hardly $30.38 \%$ employees. Majority $(42.31 \%)$ had a perception that this program is conducted monthly which is altogether a misinformation, other answers received were bi-annually or no specific time as shown in Figure 4.

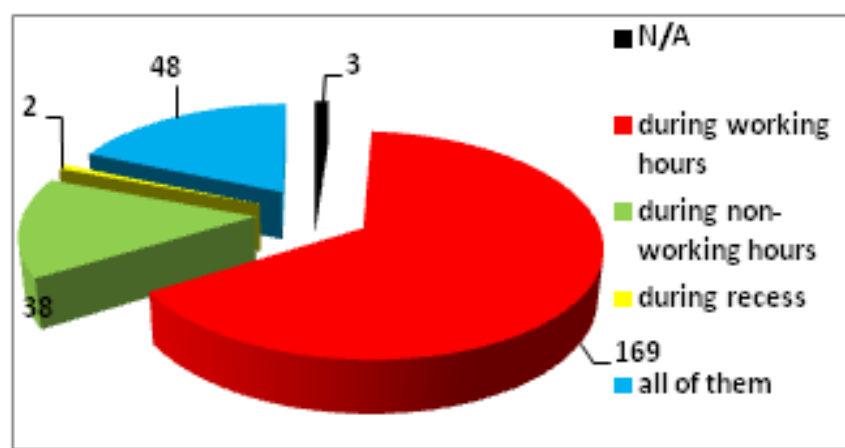

Figure 5: When is performance appraisal conducted?

Figure 5 depicts the awareness of time in a day when this program is conducted, with majority (65\%) claiming it to be conducted in working hours and a declining share of answers as any time (18.46\%), non-working hours (14.62\%) or free time $(0.77 \%)$.

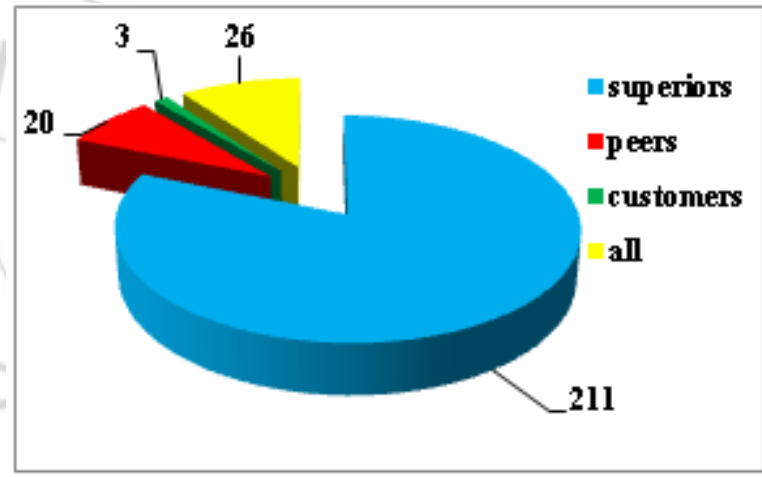

Figure 6: Who is responsible for conducting performance appraisal program?

$81.15 \%$ employees were well aware that Performance Appraisal system is being conducted by superiors of the organization. Other answers obtained are depicted in Figure 6.

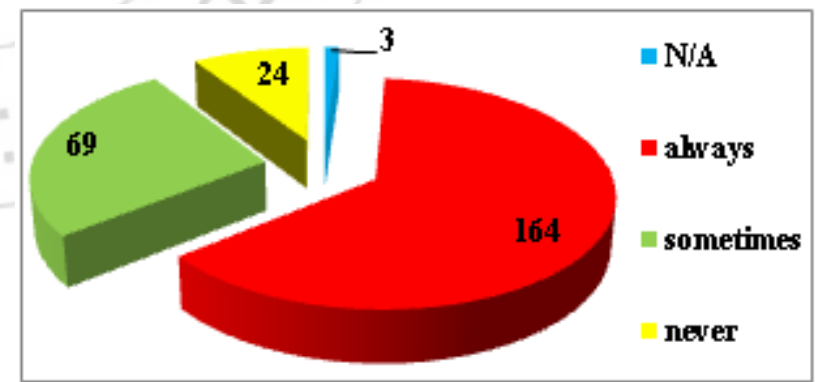

Figure 7: Are you informed of the P/A before conduction?

$63.08 \%$ employees accepted the fact that they are well informed via an email before the performance appraising starts, whereas $9.23 \%$ denied it flatly. The results are depicted in Figure 7. 


\section{International Journal of Science and Research (IJSR) \\ ISSN (Online): 2319-7064}

Index Copernicus Value (2013): 6.14 | Impact Factor (2015): 6.391

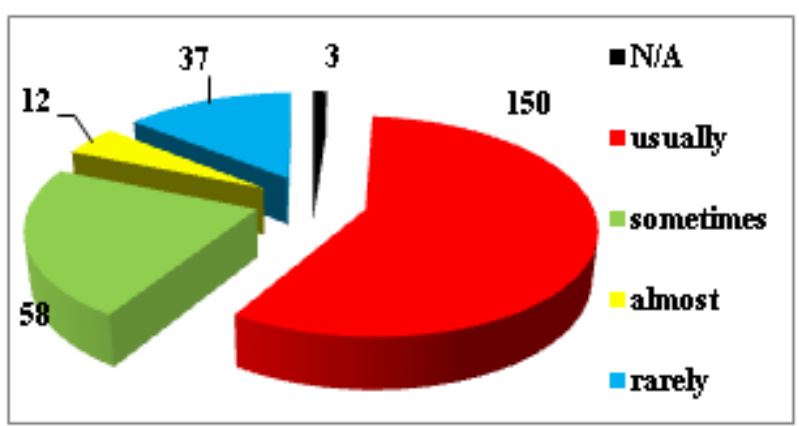

Figure 8: Do you think incentives are given strictly on basis of performance appraisal system?

Majority of the employees $(84.62 \%)$ were satisfied with the fact that incentives were being awarded on the basis of results of the program whereas $14.23 \%$ employees still refuted the same as shown in the figure 8 .

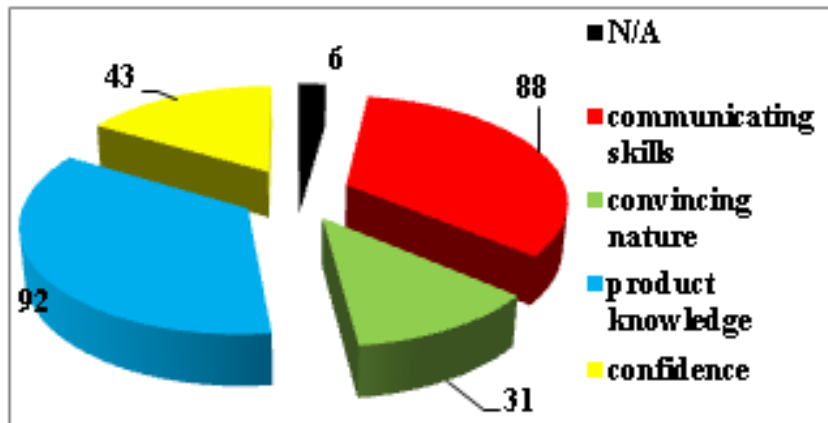

Figure 9: Performance appraisal is conducted by considering and evaluating which of the following factor?

Figure 9 projects the perceptions of the employees regarding the variables considered in Performance Appraisal. 35.38\% employees considered product knowledge, $33.85 \%$ considered communication skills, $16.54 \%$ claiming confidence and lastly, $11.92 \%$ considers convincing nature to be the important factors utilized in this program.

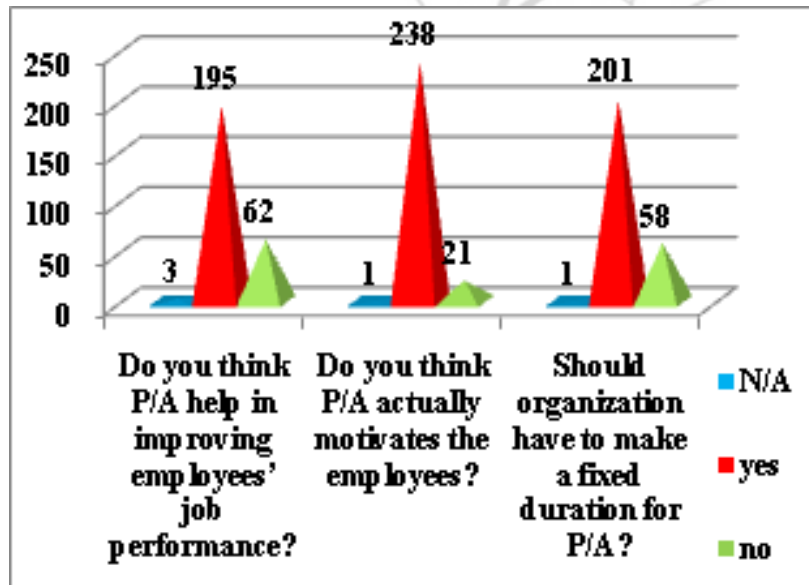

Figure 10: Do you think P/A help in improving employees' job performance?

Figure 10 projects the perception of the employees towards the effectiveness of the performance appraisal system in the institution. There was an altogether positive perception of employees in role of performance appraisal in improving employees' job performance with $75 \%$ agreeing with the same. Even more satisfying was the role of performance appraisal in motivating the employees agreed upon by 91.54\%. $77.31 \%$ employees suggested that the organization should fix up a time of the year for conduction of performance appraisal system unlike conduction in any time of the year.

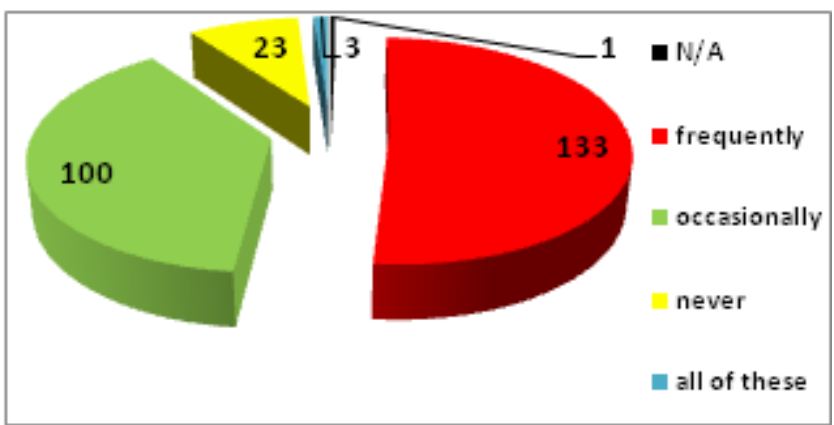

Figure 11: Is performance appraisal system reviewed and updated now and then?

$51.15 \%$ employees believed that performance appraisal system is reviewed frequently according to the latest norms, unlike $8.85 \%$ who denied any such reviews and updations. Other replies were depicted in Figure 11.

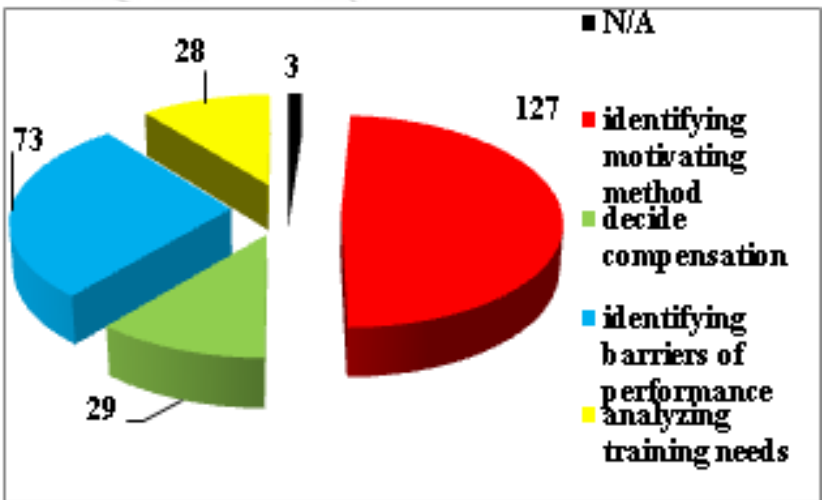

Figure 12: What is the reason for conducting $\mathrm{P} / \mathrm{A}$ in your organization?

48.84\% listed performance appraisal as a tool of motivation, $28.08 \%$ reasoned performance appraisal to be helpful in identifying barriers of performance and removing them, $11.15 \%$ consider performance appraisal conduction to be a tool to decide compensation and lastly $10.76 \%$ consider it to be a method of analyzing training needs for employees.
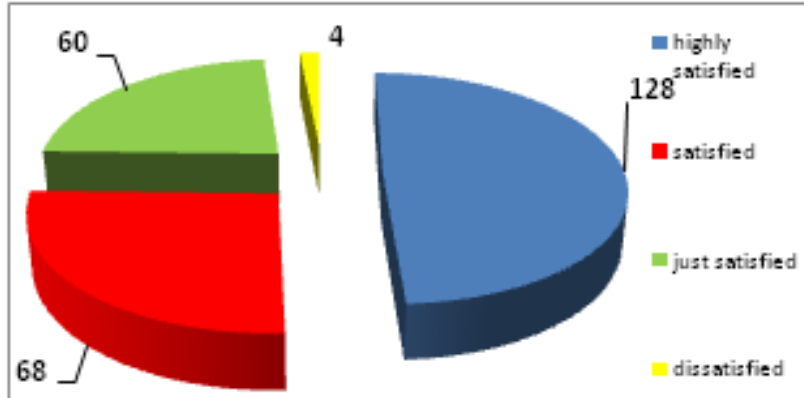

Figure 13: Are you satisfied with the current $\mathrm{P} / \mathrm{A}$ system?

Figure 13 depicts the high level of positive perception of employees $(98.46 \%)$ towards current performance appraisal system with only $1.54 \%$ dissatisfied which shows an 


\section{International Journal of Science and Research (IJSR) \\ ISSN (Online): 2319-7064}

Index Copernicus Value (2013): 6.14 | Impact Factor (2015): 6.391

effective and efficient, bias free performance appraisal program of the hospital.

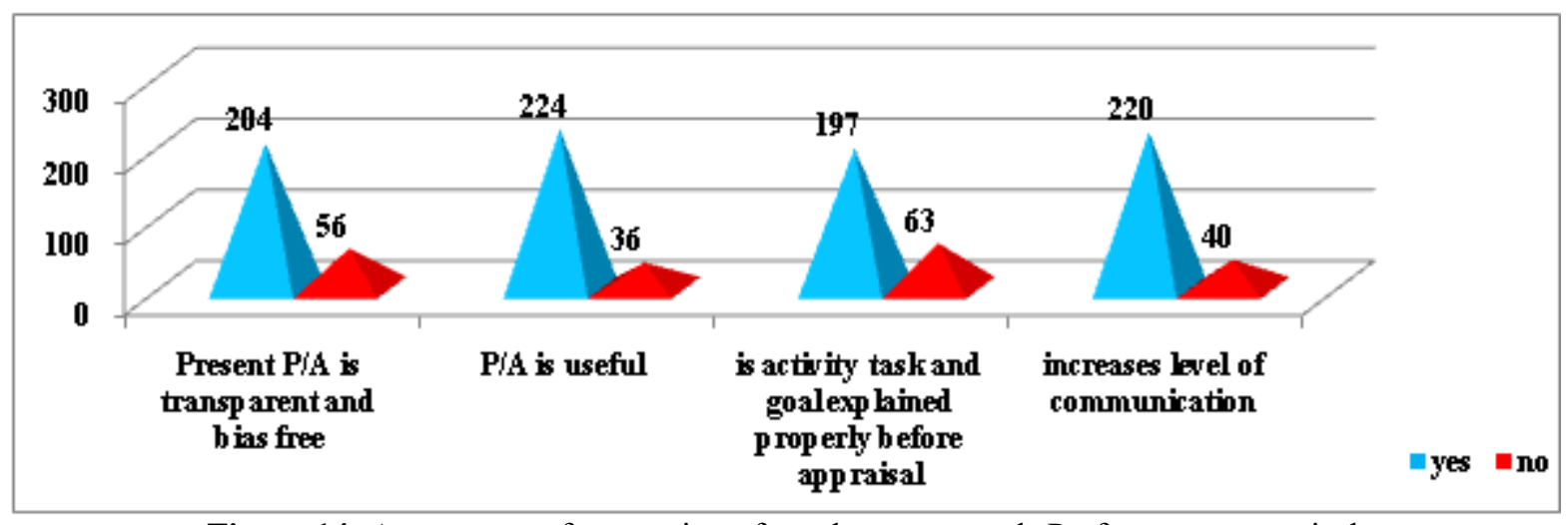

Figure 14: Assessment of perception of employees towards Performance appraisal

$75.77 \%$ employees agreed that they were informed clearly about the activity task and goals before program is conducted whereas $24.23 \%$ employees disagreed with the same. Overall a positive perception of employees was deduced regarding the program where $78.46 \%$ employees tagged this program to be transparent and bias freed. $86.15 \%$ employees consider performance evaluation to be useful with special reference to increasing level of communication (84.61\%). The employees do feel that personal bias and personal likings/ disliking of the superiors do creep in and are inherent in the appraisal system. The results are collated in Figure 14.

\section{Conclusion}

The results revealed an above normal level of awareness and high level of satisfaction of employees towards the performance appraisal system in the organization. However the awareness of the system and its methods along with objectives should be specified clearly in the orientation programs of the employees so that the employees clearly know what to do and how to send feedback in order to make this appraisal system even more useful. Last but not the least to make this program effective motivational tool, personal biasing and likes/dislikes should be kept aside during the procedure to tap the full potential of the ones who deserve.

\section{References}

[1] VV Sarma, SR Rao, "Potential Appraisal System- An Emerging Approach to Organizational Development", HRM Review, pp: 59-67, September 2004.

[2] Heyel, "The concept of performance appraisal", adapted from www.ukessays.com/essays/business/the-conceptof-performance-appraisal.php. Viewed on 23 March, 2015.

[3] J Purcell, S Hutchinson, "Front line managers as agents in the HRM- performance casual chain: theory, analysis and evidence", Human Resource Management Journal, vol. 17(1): 3-20, 2007.

[4] V Jeyasutharsan, N Rajasekar, "linkage between performance-based pay and organizational performance: an empirical study", International Journal of commerce, Business and management, 400-406, 2013.
[5] M Renton, "Increased productivity through effective performance management", People dynamics, vol.18:41, 2000.

[6] Cambridge Business English Dictionary. Adapted from www.dictionary.cambridge.org.

[7] R Teratanavat, RE Raitano, BH Kleiner, "How to reduce employee stress", Non-Profit World, vol.24(3):22, 2006

[8] MH Ishaq, MZ Iqbal, A Zaheer, "Effectiveness of performance appraisal: its outcomes and determinants in Pakistani Organization", European Journal of Social Science, vol. 10(3), 2009.

[9] IM Jawahar, "The Influence of perceptions of fairness on performance appraisal reactions", Journal of Laboratory research, vol.28(4):735-754, $1^{\text {st }}$ September 2007.

[10]N Abdelhadi, A Drach-Zahavy, "Promoting patientcare: work engagement as a mediator between ward service, climate and patient-centered care," Journal of Advanced Nursing, vol. 68(6):1276-1287, $1^{\text {st }}$ June, 2012.

[11] G Roberts, "Employee Performance Appraisal System Participation, A Technique that works in public personnel management," vol. 32(1):89-98, 2003.

[12] GB Chaudhary, S Puranik, "A study on employee performance appraisal in healthcare." Asian Journal of Management Science, vol. 2(3):59-64, 2014. 